УДК 615.468 - $616-001.45-617.58$

DOI: $10.26435 /$ UC.V0I2(31).339

\author{
А.А. Оприщенко ${ }^{1}$, А.А. Штутин ${ }^{1}$, И.В. Коктышев ${ }^{2}$ \\ 1Республиканский травматологический центр, Донецк \\ ${ }^{2} Г 00$ ВПО «Донецкий национальный медицинский университет имени М. Горького», Донецк
}

\title{
ИСПОЛЬЗОВАНИЕ АТРАВМАТИЧНЫХ ПЕРЕВЯЗОЧНЫХ МАТЕРИАЛОВ В ПОВЯЗОЧНОМ ЛЕЧЕНИИ ОГНЕСТРЕЛЬНЫХ РАН НИЖНИХ КОНЕЧНОСТЕЙ
}

Проблема лечения огнестрельных ран, несмотря на огромный опыт, накопленный многими поколениями хирургов, продолжает сохранять актуальность. В условиях современных войн и локальных военных конфликтов значительная часть раненых лечатся повязочным методом [1, 2]. Прогресс в понимании патогенеза раневого процесса при боевой травме, появление инновационных технологий на протяжении последних десятилетий позволили существенно изменить подходы к тактике лечения огнестрельной раны [3-5]. Одним из важных достижений в данном направлении является обоснование принципов ведения ран во влажной среде [6]. Значительные изменения в практике повязочного метода лечения ран происходят в связи с созданием новых форм перевязочных материалов [7-10]. К сожалению, в условиях локального вооруженного конфликта в Донбассе доступность атравматичных перевязочных материалов (АПМ) остается крайне ограниченной. В этой связи нам представляется важным поделиться опытом применения АПМ при лечении огнестрельных ранений нижней конечности.

\section{ЦЕЛЬИССЛЕДОВАНИЯ}

Сравнительный анализ клинической эффективности лечения огнестрельных ран нижней конечности повязочным методом с применением современных атравматичных перевязочных материалов.

\section{МАТЕРИАЛ И МЕТОДЫ}

В исследование были включены 47 раненых с открытыми боевыми повреждениями нижней конечности, в лечении которых использовали современные атравматичные перевязочные материалы - исследуемая группа. Мужчин было 42, женщин - 5. Средний возраст - 33,8ะ4,2 (18$47)$ лет. В качестве контрольной группы изучали материалы лечения ран традиционными средствами (марлевыми повязками) у 38 раненых 35 мужчин и 3 женщины в возрасте 34,6士3,8 (18-
46). По тяжести ранений, срокам доставки в клинику, тактике первичных оперативных пособий группы статистически не различались. Структура тяжести повреждения кожных покровов в обеих группах представлена в таблице 1 . Как следует из приведенных данных, структура тяжести повреждения кожи в обеих группах существенно не различалась. Преобладали раны IO 2-3 (по классификации AO/ASIF) - 63,5\%.

Показаниями к повязочному лечению считали: поверхностные и малые раны; глубокие и обширные раны на этапе подготовки к закрытию; гнойные раны на этапе лечения; незаживающие раны и трофические язвы на этапе лечения.

После первичных операций во всех наблюдениях раны закрывались влажно высыхающими повязками. Учитывая ограниченные материальные возможности лечебного учреждения в нынешних условиях вооруженного конфликта, мы не имели возможности сравнительного использования АПМ зарубежных фирм и применяли материалы исключительно российского производства (ЗАО «Биотекфарм», Россия). Применение АПМ в исследуемой группе начинали с 3-х суток от момента ранения. Выбор вида повязки осуществляли в соответствии со стадией клинического течения раневого процесса и местной оценкой состояния раны на основании визуальной классификации BYRP [11-13]. В соответствии с данной классификацией «B» (Black - черный - соответствует наличию сухого некроза), «Y» (Yellow - желтый - соответствует наличию плотных фибринных наложений и некротизированной клетчатки). Обе эти группы можно соотнести с фазой экссудации. При этом большое значение придается качественной оценке объема экссудации (скудная, умеренная, обильная), которая влияет на дифференцированный выбор

(c) А.А. Оприщенко, А.А. Штутин, И.В. Коктышев, 2019 (c) Университетская Клиника, 2019 
Таблица 1.

Распределение раненых по степени первичного поражения кожных покровов согласно классификации AO/ASIF

\begin{tabular}{lcccccc}
\hline \multicolumn{1}{c}{ Группа/Вид повреждения } & IO 1 & IO 2 & IO 3 & IO 4 & IO 5 & Всего \\
\hline \hline Исследуемая группа & 4 & 14 & 16 & 8 & 5 & 47 \\
\hline Контрольная группа & 3 & 12 & 12 & 5 & 6 & 38 \\
\hline Всего & 7 & 26 & 28 & 13 & 11 & 85 \\
\hline
\end{tabular}

вида перевязочного средства и частоту смен повязки. Индексы «R» (Red - красный) и «P» (Pink - розовый) описывают вид и цвет грануляций и соответствуют фазам пролиферации и эпителизации раны.

Закрытие «свежих» ран проводили сетчатыми повязками «ПараПран» с хлоргексидином или «ВоскоПран» с мазью левомеколь, что обеспечивало атравматичность и безболезненность перевязок, а также позволяло надежно изолировать рану. В фазе экссудации выбор вида перевязочного материала определялся объемом и характером раневого отделяемого. При умеренной экссудации предпочтение отдавали повязкам «ВоскоПран» с мазями левомеколь или диоксидина. При обильной экссудации - сорбирующим повязкам «ВоскоСорб» или «МедиСорб». Для проведения химической некрэктомии (Black, Yellow по BYRP) предпочтение отдавали повязкам «ПараПран» с химотрипсином. Защита от высыхания обнаженных крупных сухожилий, капсулы сустава, костных отломков достигалась созданием влажной среды с помощью гидрогелевого покрытия «ГелеПран» или пленочных покрытий «ПолиПран». Так же пленочное покрытие использовалось для создания влажной среды при «сухих» ранах. В фазе пролиферации (R- Red по BYRP) наиболее широко использовали повязки «ВоскоПран» с метилурацилом или мазью левомеколь. Этим же покрытиям отдавали предпочтение в фазе эпителизации ран. При проведении свободной аутодермопластики расщепленными трансплантатами закрытие донорских ран осуществляли биодеградируемым покрытием «ХитоПран». Отдельно следует отметить то, что при лечении обширных ран, в которых наблюдались различия в течение раневого процесса на разных участках, мы комбинировали несколько видов перевязочных материалов, что недоступно при лечении марлевыми повязками.

Эффективность лечения оценивали клиническими и планиметрическим методами.

Во всех случаях было получено информиро- ванное согласие пациентов на проведение исследований, использование материалов лечения и исследования в научно-исследовательской работе и профессиональных публикациях. Данное исследование является фрагментом плановой НИР РТЦ и одобрено местной комиссией по биоэтической экспертизе.

Результаты клинико-лабораторных исследований обработаны с помощью пакета статистических программ Statistica for Windows (StatSoft) 6.0. Сравнение количественных параметров, представленных в формате среднее \pm ошибка репрезентативности $(\mathrm{M} \pm \mathrm{m})$, проводили методом Вилкоксона для сопряженных групп.

\section{РЕЗУЛЬТАТЫ И ОБСУЖДЕНИЕ}

Анализ эффективности СПМ в сравнении с традиционным повязочным методом лечения огнестрельных ран проводился на основании клинических критериев (табл. 2.).

Представленные данные свидетельствуют о существенных преимуществах АПМ в сравнении с традиционными средствами лечения ран. Прежде всего, обращает на себя внимание меньшая болезненность перевязок (на 39,2\% по визуальной аналоговой шкале боли - ВАШ), что является одним из важных показателей оценки травматичности манипуляции. Данный эффект достигается прежде всего за счет отсутствия прилипания АПМ к раневой поверхности, что также способствует отсутствию капиллярного кровотечения из раны и сохранности формирующихся грануляций и краевого эпителия. Достоверно различались сроки последовательного перехода раны во 2 и 3 фазы раневого процесса, а также продолжительность подготовки раны к окончательному закрытию. За счет создания влажной среды в ране в 3 раза была снижена частота формирования струпа на раневой поверхности. Одним из важных преимуществ АПМ, в частности «ХитоПрана», представляется снижение продолжительности эпителизации донорской раны при выполнении аутодермопластики расщепленным трансплантатом на 35,5\%. 
Таблица 2. Сравнительная оценка эффективности СПМ в лечении огнестрельных ран нижних конечностей

\begin{tabular}{lcc}
\hline \multicolumn{1}{c}{ Показатели } & СПМ & $\begin{array}{c}\text { Традиционные } \\
\text { перевязочные средства }\end{array}$ \\
\hline \hline Болезненность перевязок (по ВАШ, в мм) & $38,6 \pm 4,2^{*}$ \\
\hline Переход во 2 фазу раневого процесса (сутки) & $23,5 \pm 5,4^{*}$ & $5,0 \pm 0,6^{*}$ \\
\hline Формирование сухого струпа после некрэктомии & $3,0 \pm 0,7^{*}$ & $60 \%$ \\
\hline $\begin{array}{l}\text { Переход в 3 фазу раневого процесса (сутки) } \\
\begin{array}{l}\text { Продолжительность подготовки раны } \\
\text { закрытию (сутки) }\end{array}\end{array}$ & $20 \%$ & $9,2 \pm 0,6^{*}$ \\
\hline $\begin{array}{l}\text { Прок эпителизации донорской раны } \\
\text { при аутодермопластике (сутки) }\end{array}$ & $7,5 \pm 0,4^{*}$ & $16,8 \pm 0,5^{*}$ \\
\hline Срок заживления раны при повязочном лечении & $12,6 \pm 0,8^{*}$ & $16,3 \pm 0,6^{*}$ \\
\hline
\end{tabular}

* - достоверность различий между группами $\mathrm{p}<0,05$

Планиметрическая оценка скорости заживления огнестрельных ран нижней конечности при применении АПМ в сравнении с традиционными средствами показало, что скорость эпителизации ран при использовании АПМ была выше на 28,7\%. Средний срок заживления ран при консервативном (повязочном) лечении составил в основной группе $18,7 \pm 2,6$ суток, а в контрольной $-24,8 \pm 2,1$ ( $\mathrm{p}<0.05)$.

Современный подход к местному лечению раны заключается в создании оптимальной для заживления среды, максимально приближенной к естественному неосложненному течению раневого процесса $[6,11,12]$. Местное аппликационное применение антисептиков и антибиотиков выявляется малоэффективным [13]. Так же убедительно не доказана эффективность локальных стимуляторов репаративного процесса (метилурацила, нуклеината натрия и др.) [13]. В настоящее время сформулированы требования к СПМ: атравматичность, способность поддержания умеренно влажной среды в ране, способность абсорбции экссудата, барьерные свойства, позволяющие изолировать рану от присоединения воздушно-капельной инфекции, возможность обеспечения газообмена раны и окружающей среды [14]. Очевидно, что в различной стадии раневого процесса те или иные характеристики приобретают большее значение. Можно сказать, что не существует единственного универсального средства для лечения ран. Выбор перевязочного материала определяется многими факторами - стадией раневого процес- са, локальной характеристикой раны, состоянием пациента и рядом иных. Рациональная тактика местного лечения раны представляется таким же искусством, как и медикаментозная терапия, требующим вдумчивого и индивидуализированного подхода. Стандартные алгоритмы применения тех или иных АПМ, предлагаемые различными производителями, далеко не всегда учитывают все многообразие локальных параметров раны, не могут и не должны восприниматься врачом в качестве «истины в последней инстанции». Динамическое наблюдение за раной, понимание процессов, в ней происходящих, являются залогом рационального выбора лечебной тактики.

\section{В Ы В 0 Д Ы}

Современные атравматичные перевязочные материалы обладают существенными преимуществами перед традиционными марлевыми повязками - меньшей травматичностью и болезненностью перевязок, ускорением перехода в последующие фазы раневого процесса.

Тактика применения современных перевязочных материалов должна носить дифференцированный и индивидуализированный характер в зависимости от стадии раневого процесса и локальных характеристик раны.

Применение современных атравматичных перевязочных материалов позволяет сократить сроки заживления огнестрельных ран нижней конечности в среднем на 32,7\%. 


\section{А.А. Оприщенко ${ }^{1}$, А.А. Штутин ${ }^{1}$, И.В. Коктышев ${ }^{2}$}

${ }^{1}$ Республиканский травматологический центр, Донецк

${ }^{2}$ ГОО ВПО «Донецкий национальный медицинский университет имени М. Горького», Донецк

\section{ИСПОЛЬЗОВАНИЕ АТРАВМАТИЧНЫХ ПЕРЕВЯЗОЧНЫХ МАТЕРИАЛОВ В ПОВЯЗОЧНОМ ЛЕЧЕНИИ ОГНЕСТРЕЛЬНЫХ РАН НИЖНИХ КОНЕЧНОСТЕЙ}

Цель: сравнительный анализ клинической эффективности лечения огнестрельных ран нижней конечности повязочным методом с применением современных атравматичных перевязочных материалов.

Материал и методы. В исследование были включены 47 раненых с открытыми боевыми повреждениями нижней конечности, в лечении которых использовали современные атравматичные перевязочные материалы - исследуемая группа. Мужчин было 42, женщин - 5. Средний возраст - 33,8 $\pm 4,2$ (18-47) лет. В качестве контрольной группы изучали материалы лечения ран традиционными средствами (марлевыми повязками) у 38 раненых - 35 мужчин и 3 женщины в возрасте $34,6 \pm 3,8$ (18-46). Преобладали раны IO 2-3 $-63,5 \%$

Результаты и обсуждение. Показано, что современные атравматичные перевязочные материалы обладают преимуществами перед традиционными марлевыми повязками - меньшей травматичностью и болезненностью перевязок (на 39,2\% по ВАШ), ускорением перехода в последующие фазы раневого процесса (на 28,5\%) и позволяют сократить сроки заживления огнестрельных ран нижней конечности в среднем на $32,7 \%$.

Заключение. Тактика применения современных перевязочных материалов должна носить дифференцированный и индивидуализированный характер в зависимости от стадии раневого процесса и локальных характеристик раны.

Ключевые слова: огнестрельные раны, лечение, современные перевязочные материалы.

\section{A.A. Oprishchenko ${ }^{1}$, A.A. Shtutin ${ }^{1}$ I.V. Koktyshev ${ }^{2}$}

${ }^{1}$ Republican Trauma Center, Donetsk

${ }^{2} S E I$ HPE «M. Gorky Donetsk National Medical University», Donetsk

\section{USE OF ATRAUMATIC DRESSING MATERIALS IN THE CONSERVATIVE TREATMENT OF GUNSHOT WOUNDS OF THE LOWER EXTREMITIES}

Objective: a comparative analysis of the clinical effectiveness of the treatment of gunshot wounds of the lower limb by the bandaging method using modern atraumatic dressing materials.

Material and methods. The study included 47 wounded with open martial injuries of the lower limb, in the treatment of which modern atraumatic dressing materials were used - the study group. There were 42 men and 5 women. The average age was $33.8 \pm 4.2(18-$ 47 ) years. As a control group, wound treatment materials were studied using traditional means (gauze bandages) in 38 wounded -35 men and 3 women aged $34.6 \pm 3.8$ (18$46)$. Wounds of IO $2-3-63.5 \%$ prevailed.

Results. It is shown that modern atraumatic dressing materials have advantages over traditional gauze bandages - less traumatic and painful dressing materials (by $39.2 \%$ according to VAS), speeding up the transition to the subsequent phases of the wound process (by 28.5\%) and reduce the healing time of gunshot wounds by an average of $32.7 \%$.

Conclusion. The tactics of applying modern dressing materials should be differentiated and individualized, depending on the stage of the wound process and the local characteristics of the wound.

Key words: gunshot wounds, treatment, modern dressing materials.

\section{ЛИТЕРАТУРА}

1. Гуманенко Е.К., Самохвалов И.М. Военно-полевая хирургия локальных войн и вооруженных конфликтов: Руководство для врачей. М.: ГЭОТАР-Медиа; 2011.672.

2. Ерюхин И.А. О хирургической обработке огнестрельных ран. Военно-медицинский журнал. 1992; 1: 25-28.

3. Воробьев В.В. Патогенез и лечение огнестрельных ран мягких тканей конечностей: Дис. .д-ра мед. наук. СПб.; 1995. 356.

4. Кузин М.И., Костюченок Б.М. Раны и раневая инфекция. 2-е изд. М.: Медицина; 1990. 592.

5. Смольянников А.В., Саркисов Д.С. Некоторые вопросы учения о раневом процессе в их историческом развитии. Архив патологии. 1994; 2: 3-7.

6. Брейтман Р. Пластиковые пленочные повязки и комплексная пудра из антибиотиков в нашей практической деятельности хирурга. Раны и раневая инфекция: Тез. докл. междунар. конф. Москва; 1993: 234.

\section{REFERENCES}

1. Gumanenko E.K., Samokhvalov I.M. Voenno-polevaya khirurgiya lokal'nykh voin i vooruzhennykh konfliktov: $\mathrm{Ru}$ kovodstvo dlya vrachei. M.: GEOTAR-Media; 2011.672 (in Russian).

2. Eryukhin I.A. O khirurgicheskoi obrabotke ognestrel'nykh ran. Voenno-meditsinskii zhurnal. 1992; 1: 25-28 (in Russian).

3. Vorob'ev V.V. Patogenez i lechenie ognestrel'nykh ran myagkikh tkanei konechnostei: Dis. .d-ra med. nauk. SPb.; 1995. 356 (in Russian).

4. Kuzin M.I., Kostyuchenok B.M. Rany i ranevaya infektsiya. 2-e izd. M.: Meditsina; 1990. 592 (in Russian).

5. Smol'yannikov A.B., Sarkisov D.S. Nekotorye voprosy ucheniya o ranevom protsesse $\mathrm{v}$ ikh istoricheskom razvitii. Arkhiv patologii. 1994; 2: 3-7 (in Russian).

6. Breitman R. Plastikovye plenochnye povyazki i kompleksnaya pudra iz antibiotikov $\mathrm{v}$ nashei prakticheskoi 
7. Луцевич Э.М., Иванян А.А., Толстых Г.П., Олтаржевская Н.Д., Рыльцев В.В. Современные раневые покрытия. Москва-Смоленск; 1996. 87.

8. Парамонов Б.А., Сиделышков В.О., Татарин С.Н. и др. Новые раневые покрытия в лечении ожогов и ранений. Военно-медицинский журнал. 2002; 4: 70-73.

9. Назаренко Г.И., Сугурова И.Ю., Глянцев С.П. Рана. Повязка. Больной. Современные медицинские технологии. М.: Медицина; 2002: 102.

10. Ягельский В.П., Сугурова И.Ю., Кильченко И.И. Современные перевязочные средства в амбулаторнополиклинической практике. Военно-медицинский журнал. 2003; 7: 65-68.

11. Dale J. Wound dressings. Prof. Nurse. 1997; Vol. 12, 12, suppl.: 12-14.

12. Lait M.E., Smith L.N. Wound management: a literature review. J. Clin. Nurs. 1998; Vol. 7, 1: 1-7.

13. Удовиченко О.В., Грекова Н.М. Диабетическая стопа. М.: Практическая медицина; 2010. 272.

14. Harding K., Jones V., Price P. Topical treatment: wich dressing to choose. Diab. Metab. Res. Rev. 2000; Vol. 16, suppl. 1.: S47-S50. deyatel'nosti khirurga. Rany i ranevaya infektsiya: Tez. dokl. mezhdunar. konf. Moskva; 1993: 234 (in Russian).

7. Lutsevich E.M., Ivanyan A.A., Tolstykh G.P., Oltarzhevskaya N.D., Ryl'tsev V.V. Sovremennye ranevye pokrytiya. Moskva-Smolensk; 1996. 87 (in Russian).

8. Paramonov B.A., Sidelyshkov V.O., Tatarin S.N. i dr. Novye ranevye pokrytiya $\mathrm{v}$ lechenii ozhogov i ranenii. Voennomeditsinskii zhurnal. 2002; 4: 70-73 (in Russian).

9. Nazarenko G.I., Sugurova I.Yu., Glyantsev S.P. Rana. Povyazka. Bol'noi. Sovremennye meditsinskie tekhnologii. M.: Meditsina; 2002: 102 (in Russian).

10. Yagel'skii V.P., Sugurova I.Yu., Kil'chenko I.I. Sovremennye perevyazochnye sredstva $\mathrm{V}$ ambulatorno-poliklinicheskoi praktike. Voenno-meditsinskii zhurnal. 2003; 7: 65-68 (in Russian).

11. Dale J. Wound dressings. Prof. Nurse. 1997; Vol. 12, 12, suppl.: 12-14.

12. Lait M.E., Smith L.N. Wound management: a literature review. J. Clin. Nurs. 1998; Vol. 7, 1: 1-7.

13. Udovichenko O.V., Grekova N.M. Diabeticheskaya stopa. M.: Prakticheskaya meditsina; 2010. 272 (in Russian).

14. Harding K., Jones V., Price P. Topical treatment: wich dressing to choose. Diab. Metab. Res. Rev. 2000; Vol. 16, suppl. 1.: S47-S50. 